\title{
TREATMENT OF IMPAIRED CORONARY BLOOD FLOW AFTER AORTIC ROOT REPLACEMENT WITH HUMAN TISSUE VALVES
}

Karl M. Dossche, MD, ${ }^{\mathrm{a}}$ Aart Brutel de la Rivière, MD, PhD, ${ }^{\mathrm{a}}$ Wim J. Morshuis, MD, PhD, ${ }^{\text {a }}$ Marc A. Schepens, $\mathrm{MD}, \mathrm{PhD},{ }^{\mathrm{a}}$

Egbert T. Bal, MD, ${ }^{\mathrm{b}}$ and Sjef M. Ernst, MD, PhD, ${ }^{\mathrm{b}}$ Nieuwegein, The Netherlands

Aortic root replacement has been described extensively for aortic allograft or pulmonary autograft insertion. ${ }^{1,2}$ One of the critical issues of this technique is the correct reimplantation of the coronary artery buttons. Kinking or torsion of the coronary arteries may lead to intraoperative hemodynamic problems or to delayed symptoms including angina pectoris and/or limited exercise tolerance owing to impaired blood flow to the myocardium. We describe our experience with and treatment of coronary malperfusion in 4 patients who underwent aortic allograft or pulmonary autograft root replacement.

\section{Clinical summaries}

PATIENT 1. A 37-year-old woman underwent pulmonary autograft root replacement for aortic valve regurgitation resulting from healed native valve endocarditis. Preoperative coronary angiography showed normal coronary arteries. During the operation, a bicuspid noncalcified aortic valve was found. The ostium of the left coronary artery (LCA) was in its normal position, but the ostium of the right coronary artery (RCA) was displaced toward the noncoronary sinus.

From the Departments of Cardiothoracic Surgery a and Cardiology, ${ }^{\mathrm{b}} \mathrm{St}$ Antonius Hospital, Nieuwegein, The Netherlands.

Received for publication Oct 19, 1998; accepted for publication Dec 23, 1998.

Address for reprints: Karl M. Dossche, MD, Department of Cardiothoracic Surgery, St Antonius Hospital, Koekoekslaan 1, 3435 CM Nieuwegein, The Netherlands.

J Thorac Cardiovasc Surg 1999;117:1034-5

Copyright (C) 1999 by Mosby, Inc.

$0022-5223 / 99 \$ 8.00+0 \quad \mathbf{1 2 / 5 4 / 9 6 7 2 0}$

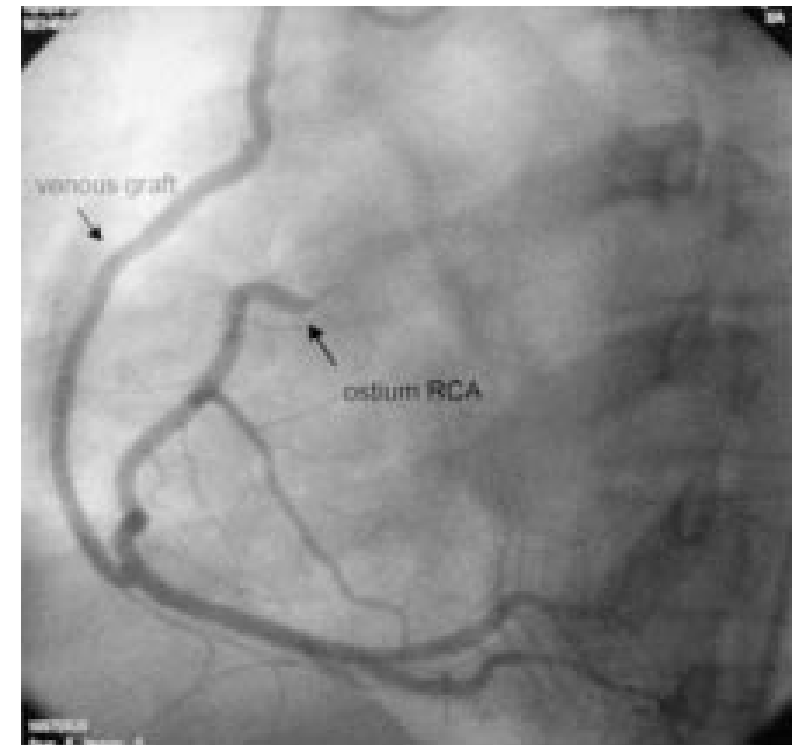

Fig 1. Postoperative coronary angiogram: Patent venous graft to the RCA, and ostial occlusion of the native RCA.

Postoperatively, she had angina pectoris and the electrocardiogram showed ST-segment depression in the inferior leads. Coronary angiography depicted kinking of the reimplanted RCA causing an ostial stenosis of $70 \%$. The RCA was stented with a $3.5 \mathrm{~mm}$ stent, which restored normal anatomy. Dobutamine stress echocardiography revealed normal functioning of all left ventricular segments. Two years after stent 


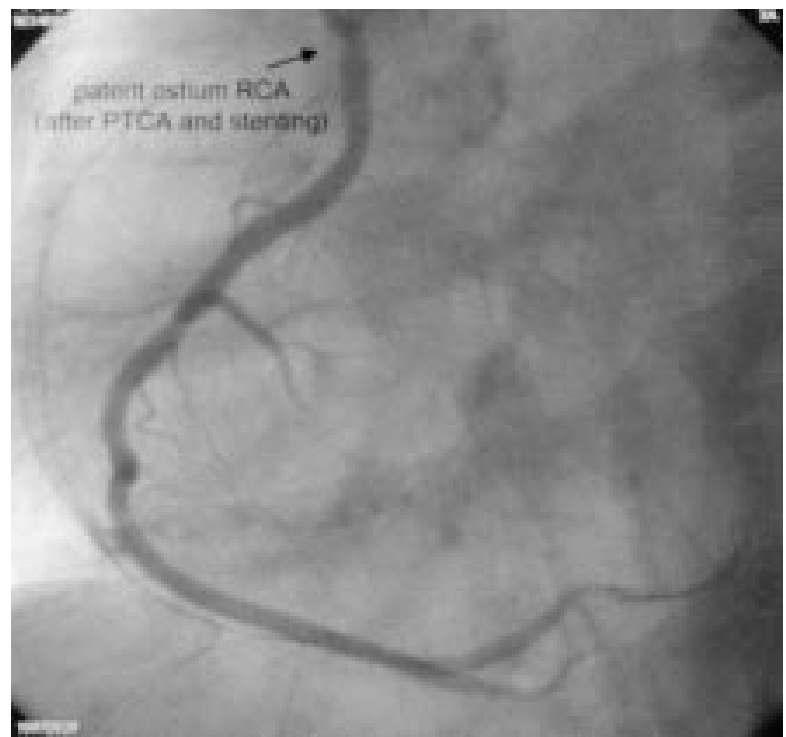

Fig 2. Contrast injection in the native RCA after percutaneous transluminal coronary angioplasty (PTCA) and stent implantation: The ostium of the RCA is patent without significant stenosis.

implantation, the patient is in New York Heart Association functional class I.

PATIENT 2. A 43-year-old woman had symptomatic aortic valve stenosis. The coronary arteries were normal. The native aortic valve was tricuspid and severely calcified. The position of the ostium of the RCA was normal. The ostium of the LCA was displaced toward the noncoronary sinus. After discontinuation of cardiopulmonary bypass (CPB), right ventricular distention occurred, suggesting malperfusion of the RCA. $\mathrm{CPB}$ was reinstituted and a saphenous vein graft was attached to the RCA. A second attempt to wean patient from CPB was not successful, this time because of left ventricular failure. The electrocardiogram showed ischemia, suggesting malperfusion of the LCA. The heart was rearrested and the left internal thoracic artery was freed and grafted to the left anterior descending coronary artery. Another segment of saphenous vein was grafted to a marginal branch of the circumflex coronary artery. Coronary angiography revealed an ostial occlusion of the RCA (Fig 1), a 50\% stenosis of the LCA, and patent grafts. The ostium of the RCA was dilated and stented successfully through the venous graft (backdoor procedure) with a 3.5-mm diameter stent (Fig 2); the ostium of the LCA was not addressed. The patient had an uneventful recovery. Postoperative transthoracic echocardiography showed normal left ventricular function.

PATIENTS 3 and 4. A 41-year-old man who underwent aortic root replacement with an aortic allograft and another 33-yearold man who underwent aortic root replacement with the pulmonary autograft had clinical signs of coronary malperfusion between 5 days and 2 months after the operation. Both underwent coronary angiography. A pinpoint ostial stenosis of the RCA was found in one patient, and a $90 \%$ ostial stenosis of the LCA in the other patient. Both patients were treated successfully by percutaneous transluminal coronary angioplasty and stent implantation.

Discussion. Aortic root replacement with an aortic allograft was first performed by Ross in 1972. Initially in all aortic allograft procedures, and later in all pulmonary autograft procedures, we used the root replacement technique. In the setting of limited availability of different sizes of cryopreserved aortic allografts in our country, the root replacement technique is the best option to overcome size discrepancies between the native aortic anulus and the available aortic allograft. Operative morbidity has been related mainly to two problems: the position of the coronary vessels and trauma to the conducting tissue. ${ }^{3}$ The true incidence of coronary malperfusion after aortic root replacement is unknown. In our series of 215 allograft and autograft root procedures with a complete follow-up, $4( \pm 2 \%)$ patients had coronary malperfusion during or after the operation. Full-thickness coronary buttons (diameter 5-6 mm) were created in all patients. Before complete mobilization of the coronary buttons, 6- 0 polypropylene stay sutures were used to avoid torsion. A single 6-0 polypropylene running suture without reinforcement was used to reimplant the coronary artery buttons. Reimplantation of the LCA was always done on a nonpressurized aortic root. In all allograft root procedures, the recipient LCA was attached to the left coronary orifice of the graft. However, once the aortic root becomes distended, small displacements may result in kinking or stretching. Because of the variability in position of the $\mathrm{RCA}$, the appropriate site for anastomosis of the RCA is more difficult to determine. It has been advocated that the distal allograft anastomosis be completed and the aortic root pressurized by releasing temporarily the aortic crossclamp before reattaching the RCA button to the allograft. ${ }^{1,4}$ We have done this only on occasions. After complete mobilization of the $\mathrm{RCA}$, the site of reimplantation always coincided with the existing right coronary orifice of the allograft root. If coronary malperfusion is suspected during the operation, coronary artery bypass grafting should follow. If coronary malperfusion is encountered only after the operation, a diagnostic coronary angiogram and invasive cardiologic intervention should follow promptly. In 3 of 4 patients, angioplasty and stent implantation followed shortly ( $<10$ days) after the operation without complications resulting from these procedures. If allograft availability (ie, with congruent sizes) will allow subcoronary implantation, this complication will be eliminated.

\section{REFERENCES}

1. Okita Y, Franciosi G, Matsuki O, Robles A, Ross DN. Early and late results of aortic root replacement with antibiotic-sterilized aortic homograft. J Thorac Cardiovasc Surg 1988;95:696-704.

2. Stelzer P, Jones DJ, Elkins RC. Aortic root replacement with pulmonary autograft. Circulation 1989;80(Suppl):III209-13.

3. Somerville J, Ross D. Homograft replacement of aortic root with reimplantation of coronary arteries. Br Heart J 1982;47:473-82.

4. Hopkins RA, Reyes A, Carpenter GA, et al. Ventricular outflow tract reconstructions with cryopreserved cardiac valved homografts: a single surgeon's ten-year experience. Ann Surg 1995; 223:544-54 